\title{
The changing landscape of economy: social and technological progress in explaining the informational efficiency of capital markets
}

\author{
Iuliana URSU \\ West University of Timisoara, Timisoara, Romania \\ iuliana.m.ursu@gmail.com
}

\begin{abstract}
In today's ever-changing landscape of economy, one of the fundamental problems remains whether market mechanisms are functioning in an efficient way, and which are the variables impacting those levels of efficiency. The main objectives of the present paper are to contribute to a better understanding of market mechanisms, by testing the Efficient market hypothesis on its weak form at a macroeconomic level, and to assess the impact of technological and social progress, measured through different variables, on markets informational efficiency. We use an adapted version of L. Kristoufek si M. Vosvrda (L. Kristoufek, M. Vosvrda, 2013, 184) methodology for Efficiency Index, based on long term memory (using 2 estimators), fractal dimension (using 11 estimators), and entropy (estimated through the approximate entropy), in order to assess the levels of efficiency for 20 market indices from both developed and emerging or frontier economies, from the Eurasia region. Further on, by using the Bayesian Model Averaging (BMA), we study the impact of technological and social progress on markets informational efficiency. Main results of the study reveal the existence of a market dynamics characterized by areas with distinctive levels of "informational efficiency", within both developed and emerging economies, encompassing a non-negligible link between past and present, persistence or anti-persistence, and a high data complexity. Moreover, while studying the relationship between market efficiency and social and technological progress, we observe that variables such as Government Effectiveness, or Control of Corruption, have a positive impact on the levels of efficiency of capital markets, while most of the technological progress estimators (amongst which Computer, communications and other services (\% of commercial service exports), or Individuals using the Internet (\% of population)), have a negative impact, translated into a decrease of informational market efficiency on the short run ( the rise of high frequency trading).
\end{abstract}

Keywords: market efficiency, high frequency trading, efficiency index, technological progress, social progress, worldwide governance indicators (WIG), adaptive market hypothesis.

\section{Introduction}

While the efficient market hypothesis has been long tested, we focus our present study on the evolutionary perspective, as defined by the adaptive market hypothesis, postulated by MIT Professor Andrew Lo, respectively under the presumption that the functioning of the financial markets is carried out under conditions of non-uniform informational efficiency, which changes along their evolutionary trajectory. These changes occur both under the impact of structural, functional, technological and institutional factors, as well as due to factors of a psychological and socio-behavioral nature.

In order to do so, we first construct an efficiency index, using an adapted version of the methodology proposed by Kristoufek and Vosvrda (2014) ${ }^{1}$, and secondly, we study the relationship between markets informational efficiency and the technological and social progress factors (as explicative variables of market efficiency).

\footnotetext{
${ }^{1}$ Kristoufek, Ladislav, and Miloslav Vosvrda. "Measuring Capital Market Efficiency: Long-Term Memory, Fractal Dimension and Approximate Entropy." The European Physical Journal B 87.7 (2014): n. pag. Crossref. Web.
} 
Under the light of the adaptive market hypothesis, in the present paper, we will try to assess wether or not variables partaining to the social and technological sphere, in the sense of progress, are affecting the efficiency levels of the considered markets.

We assess technological progress through 5 indicators: (1) Individuals using the Internet (\% of population); (2) Mobile cellular subscriptions (per 100 people); (3) Computer, communications and other services (\% of commercial service exports); (4) ICT goods exports (\% of total goods exports); and (5) High-technology exports (\% of manufactured exports). As expected, technological progress comes with both positive and negative effects, as it affects the evolution of market structures, it contributes to the improvement of trading functions in terms of speed, capacity and sophistication, and it is linked with the rise of high-frequency trading (HFT), on the short run.

Taking into account that social progress is a complex concept, encompassing multiple connotations developed within the social sphere science, we use a series of factors, pertaining to two estimative approaches of social development: in terms of governance, by using the Worldwide Governance Indicators (WGI), defined according to the World Bank, and in terms of social wellbeing, by using the Sustainable Development Goals (SDGs), and the economic prosperity indicators.

We find that both technological progress, as well as social progress, are statistically significant variables for explaining the dynamics of capital markets in terms of informational efficiency.

\section{Literature review}

Since it was first published, the efficient market hypothesis has become the foundation of modern finances. The theory, postulated by Eugene Fama in 1965, summarized in the epigram "asset prices fully reflect all available information ", sparked controversy within economic researchers, in regard to its main postulates: rationality, constant distribution of income and the positive relationship between risk and profitability.

During the time, EMH has been long criticised, by theoreticians and schools of thoughts such as behavioural finance, a field that emerged along with the empirical studies developed by psychologists Daniel Kahneman and Amos Tversky, which refutes the idea of rationality, momentum investing - a combinationation of fundamental and technical analysis that challenges the hypothesis that in the short run there are no serial correlations among stock prices, arguing that certain price patterns persist over time, or the fundamental analysis, which states for the fact that some valuation ratios, such as Price to earnings value or Price to Book Value, can help predict outperformance and underperformance of securities in future periods.

A critical issue regarding market efficiency hypothesis, is related to the idea of fair falue of a security, and the lack of a universally accepted analysis system of pricing stocks, as the theory assumes that all investors perceive available information in precisely the same manner, while different methods for analyzing and valuing stocks may indicate a different fair value, thus posing some problems regarding the validity of the theory. Beyond its limitations, the hypothesis was accepted over time, mainly due to the stability of the financial markets in a time-span of more than 20 years. However, the 2008 financial crisis offered new arguments to the criticism of EMH. As it suggested that financial markets may present an intrinsic functional instability.

Over the time, scientists from different spheres such as of economics, sociology, psychology, physics, tried to understand the way market mechanisms are functioning, thus generating the emergence of alternative theories. Some of these studies are reprezented by the 
Fractal Markets Hypothesis, first approached by Edgar Peters in 1994, which uses fractals, rescaling and nonlinear dynamic models to understand and explain the behaviour of price movements (Peters, 1994). Further on, Campbell, Lo and Mackinlay, (1997) propose the Relative Market Hypothesis, the hypothesis suggesting the relativity of the market, but which fails to address the behaviour of investors.

Amongst the newest approaches to the informational efficiency question, we find the evolutionary perspective, encompassed within Professor's M.I.T. Andrew Lo theory - the Adaptive Market Hypothesis (AMH), a paradigm that attempts to integrate the hypothesis of efficient financial markets with the principles of behavioural finance. Moreover, we find new perspectives on the way market mechanisms are functioning from the field of econophysics, that is trying to explain the complexity of financial markets from a „bottom up" perspective, hence „macroscopic” properties are viewed as the result of interactions at the level of the 'microscopic' constituents (Rickles, 2011, p.531-565) ${ }^{2}$.

In order to test for the market efficiency on the weak form, the present study considers the econophysics approach, and the evolutionary perspective, that states that the functioning of the financial markets is carried out under conditions of non-uniform informational efficiency, which changes along their evolutionary trajectory. These changes occur both under the impact of structural, functional and institutional factors, as well as due to factors of a psychological and sociobehavioral nature.

\section{Methodology}

The methodological part of the study encompasses two directions of research: first we test for of informational efficiency hypothesis, using an adapted version of the methodology proposed by Ladislav Kristoufek and Miloslav Vosvrda in their study entitled "Measuring capital market efficiency: long-term memory, Fractal size and approximate entropy", published in The European Physical Journal B, 87 (7), p. 162, for the creation of Efficiency index (The dependent variable of the study), and secondly we study the relationship between markets informational efficiency and the technological and social progress factors (explicative variables).

\section{Data}

We use the daily data for the closing prices of 20 market indices, from the Eurasia region, with countries pertaining to both developed and emerging/frontier economies.

Table 1. Country indices considered

\begin{tabular}{cc}
\hline ATX Index (Austria) & ISEQ Index (Ireland) \\
BEL 20 Index (Belgium) & JKSE Index (Indonesia) \\
S\&P BSE SENSEX Index (India) & KLSE Index (Malaysia) \\
CAC 40 Index (France) & KOSPI Index (South Korea) \\
FTSE 100 Index (UK) & KSE 100 Index (Pakistan) \\
FTSE MIB Index (Italy) & Nikkei 225 Index (Japan) \\
DAX Index (Germany) & OMX (Netherlands) \\
S\&P500 Index & PSEI Index (Philippines)
\end{tabular}

${ }^{2}$ Rickles, Dean (2008) Econophysics and Financial Market Complexity. 
Hang Seng Index (China)

IBEX 35 Index (Spain)
Swiss Market Index (Switzerland)

STI Index (Singapore)

Source: Authors' own research.

For both the financial data, respectively the closing prices of the listed market indices, as for the technological and social progress factors, the time frame considered is within January 2005 and December 2016, with daily frequency of the time series. The source of the data is represented by Yahoo Finance and Bloomberg for the financial series, and World Bank Data and IndexMundi for the estimation of the dependent variables.

\section{Efficiency index}

The Efficiency Index is a procedure for classifying the financial data series, based on their levels of efficiency, depending on the distance between the current market position and an ideal standpoint in terms of efficiency.

For our case, the formula for calculating the efficiency index is as follows:

E.I. $=\sqrt{\sum\left(M_{\text {Hurst }}-0.5\right)^{2}+\left(M_{F D}-1.5\right)^{2}+\left(\frac{M_{\text {ent. }}-1}{2}\right)^{2}}$

$M_{\text {Hurst }}$ - Expected Value of Hurst variable

$M_{F D}-$ Expected Value of Fractal Dimension

$M_{\text {ent. }}$ - Expected Value of Approximate Entropy

\section{Long term memory (Hurst Exponent)}

Long-term memory or long-term dependence/persistence is an important phenomenon in the analysis of time series, starting from the premise of a non-negligible dependence between the present and all the points of the past. This is usually characterized by a decay of the power law of the autocorrelation function (in the time domain), and a near-origin spectrum divergence in the frequency domain (Ursu, 2018). The characteristic feature of long-term memory is the Hurst coefficient, which varies between $0 \leq \mathrm{H}<1$ for stationary processes. The reference value of 0.5 is considered to be the benchmark of informational efficient time series, being an indicator of random processes and lack of long-term memory. In order to estimate Hurst exponent we use two indicators in $\mathrm{R}$ program: Sperio - with a model based on the regression equation using the smoothed periodogram function as an estimate of the spectral density ${ }^{3}$, and Whittle estimator, using WhittleEst function in order to compute Whittle's approximate MLE for fractional Gaussian noise or fractional ARIMA models ${ }^{4}$

\section{Fractal dimension}

The fractal dimension can be defined as a report that provides a statistical index of complexity by comparing how the details of a model change with the scale it is being measured on. It has a benchmark value of 1.5 for efficient markets.

The estimators considered for the computation of fractal dimension within the Efficiency index are according to figure 1, below:

\footnotetext{
${ }^{3}$ Reisen, V. A., B. Abraham, and E. M. M. Toscano (2001) Parametric and semiparametric estimations of stationary univariate ARFIMA model. Brazilian Journal of Probability and Statistics 14, 185-206.

${ }^{4}$ Beran, Jan (1994). Statistics for Long-Memory Processes; Chapman \& Hall. (Section 6.1, p.116-119; 12.1.3, p.223 ff)
} 


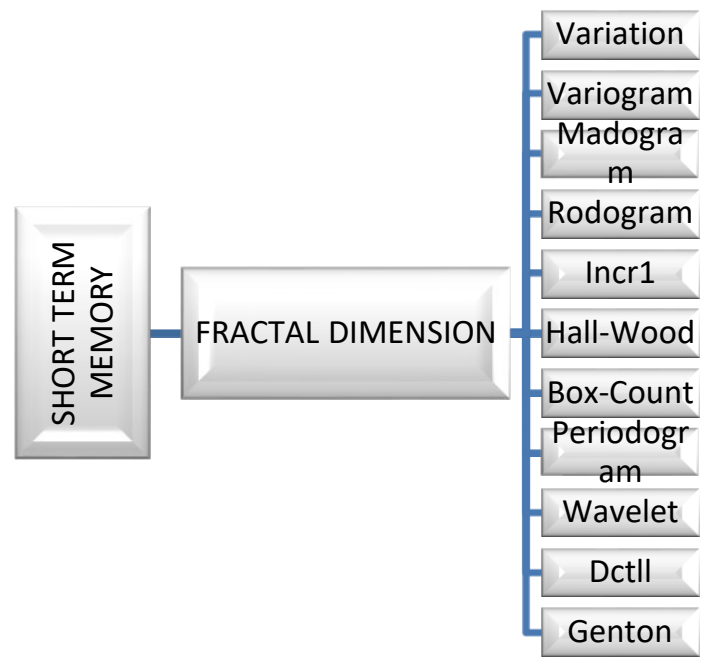

PICBE | 944

Figure 1. Estimators of fractal dimension

Source: Authors' own research.

\section{Approximate entropy}

Approximate entropy (A.E.) can be defined as a measure of the complexity of a system. The higher it is, the more random the system in question is, while a lower value suggests a more deterministic system. Efficient markets are characterized by a maximum entropy, consequently, a level of 1 . We use pracma package in R, with adapted inputs, based on Pincus methodology ${ }^{5}$.

Testing the adaptive market hypothesis

\section{Technological progress}

As explicative variable of the market informational efficiency, we assess technological progress through 5 indicators: (1) Individuals using the Internet (\% of population); (2) Mobile cellular subscriptions (per 100 people); (3) Computer, communications and other services (\% of commercial service exports); (4) ICT goods exports (\% of total goods exports); (5) Hightechnology exports (\% of manufactured exports). The source of indicators is the World Bank Data catalog. The frequency of the data is annual.

\section{Social progress}

The second frame of impact on the market informational efficiency is represented by the social development of the countries considered. As social progress is a complex concept, encompassing multiple connotations developed within the social sphere science, we use a series of factors, pertaining to two estimative approaches of social development: in terms of governance (macro impact), and in terms of social development goals and economic prosperity (with a more persistent microlevel impact).

We define governance as "traditions and institutions by which authority in a country is exercised. This includes the process by which governments are selected, monitored and replaced; the capacity of the government to effectively formulate and implement sound policies; and the

\footnotetext{
${ }^{5}$ Yentes, Jennifer \& Hunt, Nathaniel \& Schmid, Kendra \& Kaipust, Jeffrey \& Mcgrath, Denise \& Stergiou, Nicholas. (2012). The Appropriate Use of Approximate Entropy and Sample Entropy with Short Data Sets. Annals of biomedical engineering. 41. 10.1007/s10439-012-0668-3.
} 
respect of citizens and the state for the institutions that govern economic and social interactions among them." ( The Worldwide Governance Indicators)

For the measurement of governance impact, we use The Worldwide Governance Indicators (WGI), defined according to the World Bank, respectively (1) Control of Corruption (2) Government Effectiveness; (3) Political Stability and Absence of Violence/Terrorism; (4) Regulatory Quality; (5) Rule of Law. (6) Voice and Accountability (Worldwide Governance Indicators)( Kaufmann, Kraay and Mastruzzi, 2010).

In order to estimate "social wellbeing", we have chosen a series of estimates related both to the Sustainable Development Goals (SDGs), as well as economic prosperity indicators: (1) GDP per person employed (constant 2011 PPP \$) (2) Current health expenditure (\% of GDP; (3) Unemployment, total (\% of total labor force) (modeled ILO estimate (4) Ratio of female to male labor force participation rate (\%) (modeled ILO estimate) (5) Population ages 65 and above (\% of total population); (6) Mortality rate under-5 (per 1,000 live births) (7) Life expectancy at birth, total (years).

\section{Results and discussions}

The present paper aim is to compute the Efficiency Index, by using an adapted version of Kristoufek and Vosvrda (Kristoufek, Vosvrda (2014))1 methodology, and then to study the relationship between the level of efficiency of a market, and different estimators of what we defined before as being representative for technological and social progress.

The analysis is carried on 20 indices, from the Eurasia region, as defined before. The results obtained in terms of long-term memory, translated in non-negligible deviations from the benchmark value of 0.5 , suggests that both the developed and emerging markets considered are characterized by periods of inefficiency, either in a deterministic sense (persistence) or in a random-chaotic sense (anti-persistence, with more intense movements than random ones). These results contravene to the efficient market hypothesis, as they suggest a non-negligible dependence between past and the present, hence periods in which markets fail to fully incorporate in existent information.

The periods of inefficiency are also confirmed by the results obtained in the case of shortterm memory, estimated using different methods for computing the fractal dimension, as important deviations from the benchmark of 1.5 occur, especially during the financial crisis of 2008, and at the level of emerging economies, where we also find multifractality. In the case of emerging markets, the results can be explained through the fact that this type of markets are characterised a series of specific features in terms of trading mechanisms, liquidity, risk aversion of the participants, the institutional framework and the degree of integration with the mature financial markets.

A high level of data complexity and thus certain levels of inconsistency in the process of integrating existing information into the market, are suggested by the important deviations of the approximate entropy from the benchmark value of 1 .

By using the efficiency index formula, defined in the section Methodology, we estimate the annual values of the index - ranging between 0 and 1, where 0 is the benchmark status, hence the point of informational efficiency.

The results are then ranked based on the level of efficiency suggested by the index. The lowest the deviation of the market index from the efficiency level, the lowest the ranking.

Table no. 2 summarizes the results obtained at macroeconomic level in terms of efficiency index results and rankings. 
Table 2. Efficiency Index results and rankings

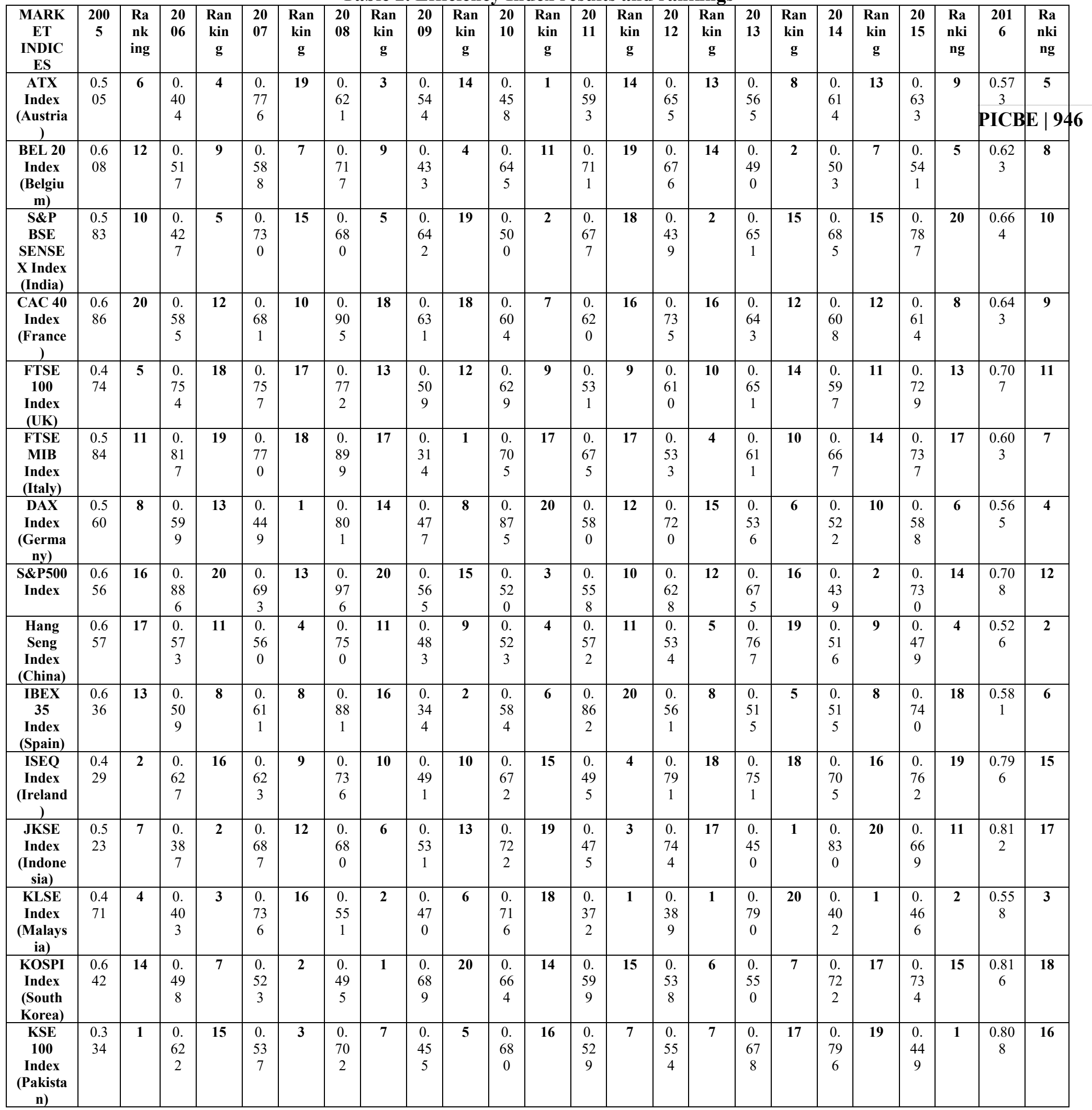




\begin{tabular}{|c|c|c|c|c|c|c|c|c|c|c|c|c|c|c|c|c|c|c|c|c|c|c|c|c|}
\hline $\begin{array}{c}\text { Nikkei } \\
225 \\
\text { Index } \\
\text { (Japan) } \\
\end{array}$ & $\begin{array}{l}0.6 \\
64\end{array}$ & 18 & $\begin{array}{c}0 . \\
51 \\
9\end{array}$ & 10 & $\begin{array}{c}0 . \\
79 \\
9\end{array}$ & 20 & $\begin{array}{c}0 . \\
80 \\
5\end{array}$ & 15 & $\begin{array}{c}0 . \\
56 \\
9\end{array}$ & 16 & $\begin{array}{c}0 . \\
63 \\
1\end{array}$ & 10 & $\begin{array}{c}0 . \\
52 \\
9\end{array}$ & 6 & $\begin{array}{c}0 . \\
52 \\
6\end{array}$ & 3 & $\begin{array}{c}0 . \\
65 \\
0\end{array}$ & 13 & $\begin{array}{c}0 . \\
46 \\
2\end{array}$ & 3 & $\begin{array}{c}0 . \\
65 \\
2\end{array}$ & 10 & $\begin{array}{c}0.86 \\
1\end{array}$ & 20 \\
\hline $\begin{array}{l}\text { OMX } \\
\text { (Netherl } \\
\text { ands) }\end{array}$ & $\begin{array}{l}0.6 \\
95\end{array}$ & 21 & $\begin{array}{c}0 . \\
66 \\
3 \\
\end{array}$ & 17 & $\begin{array}{c}0 . \\
68 \\
3 \\
\end{array}$ & 11 & $\begin{array}{c}0 . \\
76 \\
8\end{array}$ & 12 & $\begin{array}{c}0 . \\
57 \\
2 \\
\end{array}$ & 17 & $\begin{array}{c}0 . \\
62 \\
4 \\
\end{array}$ & 8 & $\begin{array}{c}0 . \\
59 \\
2\end{array}$ & 13 & $\begin{array}{c}0 . \\
79 \\
5\end{array}$ & 19 & $\begin{array}{c}0 . \\
50 \\
6\end{array}$ & 4 & $\begin{array}{c}0 . \\
48 \\
7 \\
\end{array}$ & 4 & $\begin{array}{c}0 . \\
73 \\
4 \\
\end{array}$ & 16 & $\begin{array}{c}0.78 \\
7\end{array}$ & 14 \\
\hline $\begin{array}{c}\text { PSEI } \\
\text { Index } \\
\text { (Philipp } \\
\text { ines) }\end{array}$ & $\begin{array}{l}0.5 \\
71\end{array}$ & 9 & $\begin{array}{c}0 . \\
38 \\
1\end{array}$ & 1 & $\begin{array}{c}0 . \\
56 \\
3\end{array}$ & 5 & $\begin{array}{c}0 . \\
71 \\
2\end{array}$ & 8 & $\begin{array}{c}0 . \\
47 \\
2\end{array}$ & 7 & $\begin{array}{c}0 . \\
64 \\
8\end{array}$ & 12 & $\begin{array}{c}0 . \\
42 \\
3\end{array}$ & 2 & $\begin{array}{c}0 . \\
82 \\
6\end{array}$ & 20 & $\begin{array}{c}0 . \\
61 \\
7\end{array}$ & 11 & $\begin{array}{c}0 . \\
72 \\
5\end{array}$ & 18 & $\begin{array}{c}0 . \\
72 \\
4\end{array}$ & 12 & PICA & $\mathrm{E}^{199}$ \\
\hline $\begin{array}{c}\text { Swiss } \\
\text { Market } \\
\text { Index } \\
\text { (Switzer } \\
\text { land) }\end{array}$ & $\begin{array}{c}0.6 \\
54\end{array}$ & 15 & $\begin{array}{c}0 . \\
61 \\
0\end{array}$ & 14 & $\begin{array}{c}0 . \\
69 \\
7\end{array}$ & 14 & $\begin{array}{c}0 . \\
93 \\
7\end{array}$ & 19 & $\begin{array}{c}0 . \\
50 \\
8\end{array}$ & 11 & $\begin{array}{c}0 . \\
55 \\
7\end{array}$ & 5 & $\begin{array}{c}0 . \\
50 \\
4\end{array}$ & 5 & $\begin{array}{c}0 . \\
60 \\
3\end{array}$ & 9 & $\begin{array}{c}0 . \\
60 \\
2\end{array}$ & 9 & $\begin{array}{c}0 . \\
49 \\
8\end{array}$ & 5 & $\begin{array}{c}0 . \\
58 \\
9\end{array}$ & 7 & $\begin{array}{c}0.74 \\
1\end{array}$ & 13 \\
\hline $\begin{array}{c}\text { STI } \\
\text { Index } \\
\text { (Singap } \\
\text { ore) } \\
\end{array}$ & $\begin{array}{l}0.6 \\
71\end{array}$ & 19 & $\begin{array}{c}0 . \\
44 \\
4\end{array}$ & 6 & $\begin{array}{c}0 . \\
58 \\
2\end{array}$ & 6 & $\begin{array}{c}0 . \\
66 \\
0\end{array}$ & 4 & $\begin{array}{c}0 . \\
41 \\
3\end{array}$ & 3 & $\begin{array}{c}0 . \\
66 \\
3\end{array}$ & 13 & $\begin{array}{c}0 . \\
52 \\
9\end{array}$ & 8 & $\begin{array}{c}0 . \\
62 \\
2\end{array}$ & 11 & $\begin{array}{c}0 . \\
49 \\
7\end{array}$ & 3 & $\begin{array}{c}0 . \\
49 \\
9\end{array}$ & 6 & $\begin{array}{c}0 . \\
47 \\
3\end{array}$ & 3 & $\begin{array}{c}0.40 \\
7\end{array}$ & 1 \\
\hline
\end{tabular}

Source: Authors' own research.

For a better understanding of the dynamics of deviations from market efficiency, we synthetized the results in the figures up below.

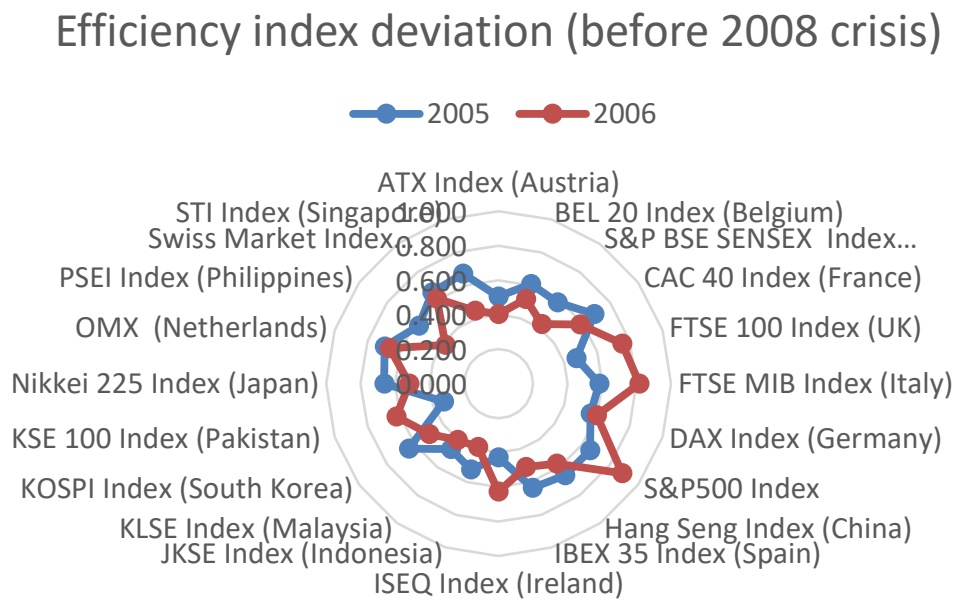

\section{Figure 2. Efficiency index deviation (before 2008 crisis)}

Source: Authors' own research.

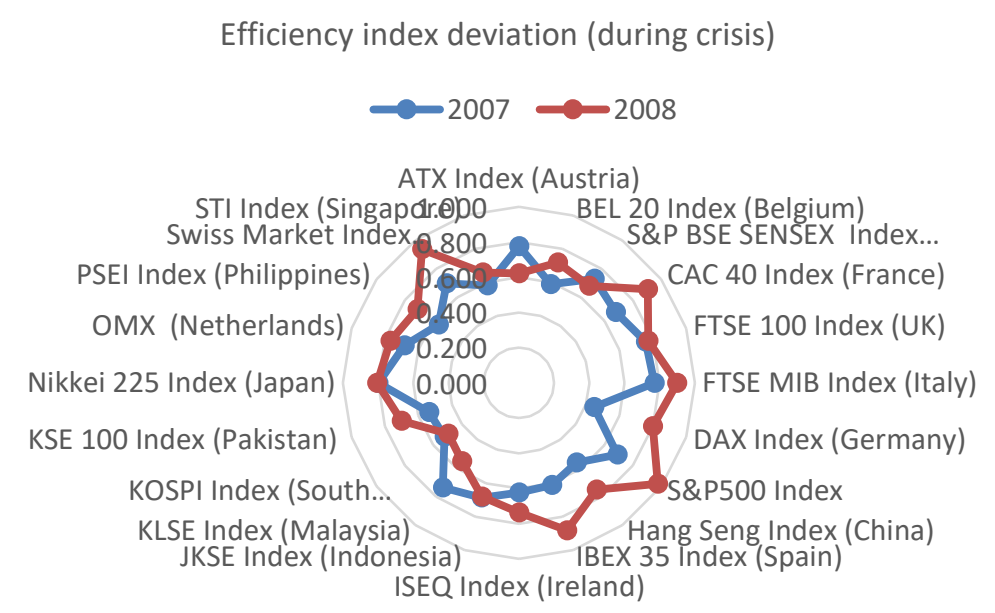

DOI: 10.2478/picbe-2020-0089, pp. 940-952, ISSN 2558-9652| Proceedings of the $14^{\text {th }}$ International Conference on Business Excellence 2020 
Figure 2. Efficiency index deviation (during crisis)

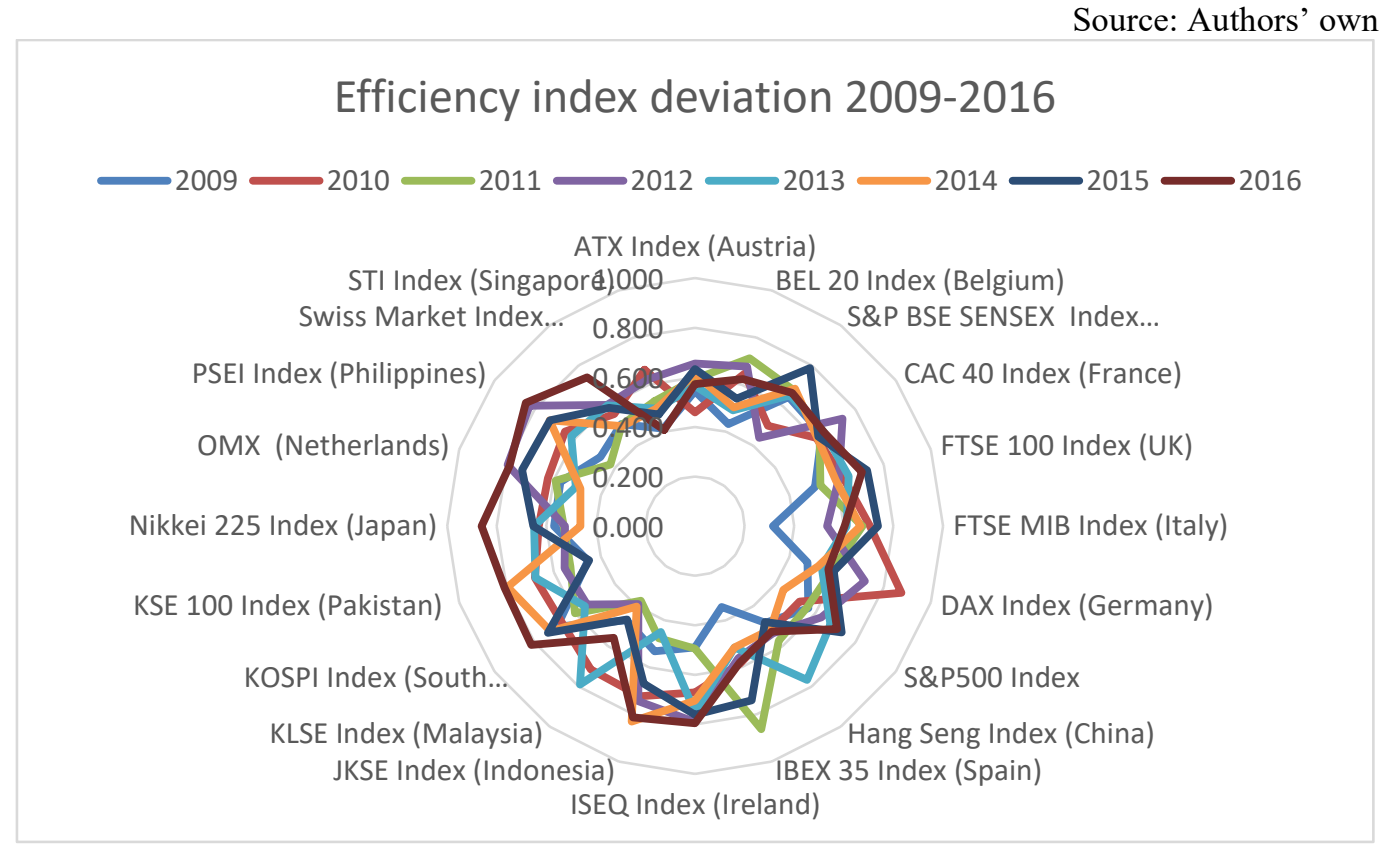

PICBE $\mid 948$

Figure 3. Efficiency index deviation (after crisis)

Source: Authors' own research.

By analyzing the results we observe that prior to the crisis the level of deviation from efficiency is more reduced, during the financial crisis it expands before eventually returning closer to the reference value following the crisis, suggesting that overtime, markets tend towards reaching an equilibrium state.

However, the presence of inefficiency intervals, especially during bubbles and periods of financial instabilities, when shocks of different nature (both exogenous and endogenous), and contagion are key aspects that characterize the international capital flows, and consequently all economies integrated in those flows (fully integrated or part of developing and frontier markets), are not consistent to the efficient market theory.

Moreover, we observe different levels of efficiency depending on the stage of the development of the markets considered, with developed markets being more efficient, and the geographical positioning of the markets, with most of the efficient economies being part of Europe.

The critical issue that the research confirms is the existence of certain shocks, of endogenous and exogenous nature, that are likely to move, on a short and a long term, the market from a "close to balance" functional area. We observe thus the existence of a financial market dynamics characterized by areas with distinctive levels of "information efficiency".

The results, which contradict the main postulates of the Efficient Market Theory, are consistent with the adaptive market hypothesis, theory that is based on the meta-hypothesis that the functioning of the financial markets is carried out under conditions of non-uniform informational efficiency, which changes along their evolutionary trajectory. Furthermore, in his study entitled "The Adaptive Markets Hypothesis", Andrew Lo claims that these changes occur both under the impact of structural, functional and institutional factors, as well as due to factors of a psychological and socio-behavioral nature (Lo, 2004). 
Under the light of the adaptive market hypothesis, in the present paper, we will try to assess wether or not variables partaining to the social and technological sphere, in the sense of progress, are affecting the efficiency levels of the considered markets.

We start from the premise that due to technological and social progress, as well as taking into account the variety of investors profiles, market efficiency is expected to vary in cyclical patterns (Kim, Shamsuddin, \& Lim, 2011, p. 868-879) ${ }^{6}$. This means that between social and technological progress, and markets efficiency should be a relationship of mutual influence.

By using the Bayesian generalized linear model, we study the correctness of the explanatory variables considered for the Efficiency Index, in terms of social and technological progress. Table 3 summarize the results of the test.

Table 3. Bayesian generalized linear model results for testing the relationship between technological and social progress, and efficiency index

\begin{tabular}{|c|c|c|c|}
\hline \multicolumn{4}{|l|}{ DEPENDENT VARIABLE: EFFICIENCY INDEX } \\
\hline EXPLANATORY VARIBALES & CATHEGORY & PIP & $\begin{array}{l}\text { POSTERIOR } \\
\text { MEAN }\end{array}$ \\
\hline $\begin{array}{l}\text { Computer, communications and other services ( } \% \text { of } \\
\text { commercial service exports) }\end{array}$ & Technological progress & $88.14 \%$ & 0.13026 \\
\hline Government Effectiveness: Estimate & $\begin{array}{l}\text { Social progress (Institutional } \\
\text { quality) }\end{array}$ & $65.33 \%$ & -0.30489 \\
\hline Individuals using the Internet ( $\%$ of population) & Technological progress & $51.52 \%$ & 0.09215 \\
\hline Control of Corruption: Estimate & $\begin{array}{l}\text { Social progress (Institutional } \\
\text { quality) }\end{array}$ & $47.83 \%$ & 0.10597 \\
\hline $\begin{array}{l}\text { High-technology exports (\% of manufactured } \\
\text { exports) }\end{array}$ & Technological progress & $47.39 \%$ & -0.04620 \\
\hline Current health expenditure ( $\%$ of GDP) & Social progress (Quality of life) & $46.76 \%$ & 0.04409 \\
\hline Voice and Accountability: Estimate & $\begin{array}{l}\text { Social progress (Institutional } \\
\text { quality) }\end{array}$ & $45.40 \%$ & 0.05180 \\
\hline ICT goods exports ( $\%$ of total goods exports) & Technological progress & $44.20 \%$ & 0.03473 \\
\hline Regulatory Quality: Estimate & $\begin{array}{l}\text { Social progress (Institutional } \\
\text { quality) }\end{array}$ & $42.69 \%$ & 0.08427 \\
\hline $\begin{array}{l}\text { Ratio of female to male labor force participation rate } \\
(\%) \text { (modeled ILO estimate) }\end{array}$ & Social progress (Quality of life) & $42.59 \%$ & 0.02824 \\
\hline GDP per person employed (constant 2011 PPP \$) & Social progress (Quality of life) & $41.21 \%$ & -0.03366 \\
\hline Mortality rate, under-5 (per 1,000 live births) & Social progress (Quality of life) & $40.86 \%$ & 0.02732 \\
\hline $\begin{array}{l}\text { Political Stability and Absence of } \\
\text { Violence/Terrorism: Estimate }\end{array}$ & $\begin{array}{l}\text { Social progress (Institutional } \\
\text { quality) }\end{array}$ & $40.51 \%$ & 0.02767 \\
\hline Rule of Law: Estimate & $\begin{array}{l}\text { Social progress (Institutional } \\
\text { quality) }\end{array}$ & $40.06 \%$ & -0.00653 \\
\hline Life expectancy at birth, total (years) & Social progress (Quality of life) & $39.54 \%$ & 0.02756 \\
\hline Population ages 65 and above ( $\%$ of total population) & Social progress (Quality of life) & $39.07 \%$ & -0.01597 \\
\hline Mobile cellular subscriptions (per 100 people) & Technological progress & $38.79 \%$ & -0.00350 \\
\hline $\begin{array}{l}\text { Unemployment, total (\% of total labor force) } \\
\text { (modeled ILO estimate) }\end{array}$ & Social progress (Quality of life) & $38.74 \%$ & -0.01039 \\
\hline
\end{tabular}

(modeled ILO estimate)

Source: Authors' own research

The results obtained by using the Bayesian generalized linear model, shows that statistically significant explanatory variables for market efficiency (as estimators of technological progress) are

\footnotetext{
${ }^{6}$ Kim, Jae H. \& Shamsuddin, Abul \& Lim, Kian-Ping, 2011. ... 18(5), pages 868-879. Handle:
}

RePEc:eee:empfin:v:18:y:2011:i:5:p:868-879

DOI: $10.2478 /$ picbe-2020-0089, pp. 940-952, ISSN 2558-9652| Proceedings of the $14^{\text {th }}$ International Conference on Business Excellence 2020 
(1) Computer, communications and other services (\% of commercial service exports), with a posterior inclusion probability (PIP) of 0.8814, and a posterior mean of 0.13026 ; and (2) Individuals using the Internet (\% of population), with a posterior inclusion probability (PIP) of 0.5152 , and a posterior mean of 0.09215 .

The positive values of the posterior mean imply a positive impact on the efficiency index, respectively an increase in Computer, communications and other services (\% of commercial service exports), and in Individuals using the Internet (\% of population), will translate into a decrease of informational market efficiency on the short run.

The results are consistent with those of the current literature: Balp and others (2018) Virgilio $(2015)^{8}$ e.t.c., regarding the impact that high-frequency trading (HFT), facilitated by the progress in the field of technology, has on the market efficiency on the short run.

While amongst some benefits of high-frequency trading (HFT) are represented by a wider participation in markets, increased liquidity, narrowed spreads, reduced short term volatility, or means for clients to obtain better execution of orders, those benefits comes with some costs, such as unpredictable errors and inaccuracies in the algorithms employed that can lead to deceptive orders, "better "nanosecond" price discovery but markets in which prices reflect less well the underlying fundamentals (Stiglitz, 2016) ${ }^{9}$, informational inequalities ( HFTs' faster access to news feeds and trading data), increased transaction costs of non HFTs, or even the negative impact on market fairness and integrity. 8 However, even thou on the short run, the technological development can have a negative impact on market quality and stability, as well as on the information equality for the market participants, the impact on the long term will depend on regulation mechanisms.

The results obtained regarding the relationship between social progress and efficiency index, shows that the only statistically significant explanatory variable for market efficiency (as estimators of social progress) is Government Effectiveness, with a posterior inclusion probability (PIP) of 0.6533 , and a posterior mean of -0.30489 . The negative value of the posterior mean infers the fact that an increase in government effectiveness will translate into a decrease of the efficiency index, hence an increase in markets informational efficiency.

Considering the results, we conclude that both technological factors, as well as social factors, can be considered as statistically relevant variables for explaining the dynamics of capital markets in terms of informational efficiency.

\section{Conclusion}

While the E.M.H. assumes a full-on efficient market, the evolutionary perspective, as defined by the adaptive market hypothesis, postulated by MIT Professor Andrew Lo, states that the functioning of the financial markets is carried out under conditions of non-uniform informational efficiency, which changes along their evolutionary trajectory. These changes occur both under the impact of structural, functional, technological and institutional factors, as well as due to factors of a psychological and socio-behavioral nature.

\footnotetext{
7 Balp, Gaia and Strampelli, Giovanni, Preserving Capital Markets Efficiency in the High-Frequency Trading Era (January 7, 2018). Bocconi Legal Studies Research Paper No. 3097723; Journal of Law, Technology and Policy, Forthcoming. Available at SSRN: https://ssrn.com/abstract=3097723 or http://dx.doi.org/10.2139/ssrn.3097723

${ }^{8}$ Virgilio, Gianluca. (2015). High-frequency trading and the efficient market hypothesis.

${ }^{9}$ Stiglitz J.E. (2016) New Theoretical Perspectives on the Distribution of Income and Wealth Among Individuals. In: Basu K., Stiglitz J.E. (eds) Inequality and Growth: Patterns and Policy. International Economic Association Series. Palgrave Macmillan, London
} 
In order to test the random walk hypothesis, or the EMH in its weak form, we construct an efficiency index, using an adapted version of the methodology proposed by Ladislav Kristoufek and Miloslav Vosvrda in their study entitled "Measuring capital market efficiency: long-term memory, Fractal size and approximate entropy"1. Based on the efficiency index results, we study the relationship between markets informational efficiency and the technological and social progress factors (as explicative variables of market efficiency).

PICBE | 951

The results at the efficiency index suggests the presence of inefficient intervals, especially during bubbles and periods of financial instabilities, when shocks of different nature (both exogenous and endogenous), and contagion are key aspects that characterize the international capital flows. Moreover, we observe different levels of efficiency depending on the stage of the development of the considered markets, with developed markets being more efficient, and the geographical positioning of the markets, with most of the efficient economies being part of Europe.

The critical issue that the research confirms is the existence of certain shocks, of endogenous and exogenous nature, that are likely to move, on a short and a long term, the market from a "close to balance" functional area. We observe thus the existence of a financial market dynamics characterized by areas with distinctive levels of "information efficiency".

The results, which contradict the main postulates of the Efficient Market Theory, are consistent with the adaptive market hypothesis, theory that is based on the meta-hypothesis that the functioning of the financial markets is carried out under conditions of non-uniform informational efficiency, which changes along their evolutionary trajectory, and these changes may occur under the impact of structural, functional and institutional factors, as well as due to factors of a psychological and socio-behavioral nature ( Lo, 2014)1.

In order to assess whether variables pertaining to social and technological sphere, in the sense of progress, are affecting the efficiency levels of the considered markets, we use the Bayesian generalized linear model.

From the variables considered we find that the statistically significant explanatory variables for market efficiency: (1) Computer, communications and other services (\% of commercial service exports), (2) Individuals using the Internet (\% of population), and (3) Government Effectiveness.

We observe that an increase in technological progress, as defined in the previous sections, implies a decrease of informational market efficiency on the short run. The results are consistent with those of the current literature: Balp and others (2018)7, Virgilio (2015)8 e.t.c., in the sense that technological progress facilitates the emergence of high-frequency trading (HFT), that has a destabilizing effect on the market efficiency, on the short run. However, the impact of technological progress on market efficiency and stability, on the long run, will depend on regulation mechanisms.

The results obtained regarding the relationship between social progress and efficiency index, shows that an increase in government effectiveness will translate into a decrease of the efficiency index, hence an increase in markets informational efficiency.

Considering the results, we conclude that both technological factors, as well as social factors, can be considered as statistically relevant variables for explaining the dynamics of capital markets in terms of informational efficiency.

Some of the limitations of the study are represented by the limited access to data, limited data for the most relevant social indicators the author was inclined to consider (Social Progress Index (SPI), Human Development Index (HDI), Standardized World Income Inequality Database (SWIID), Bertelsmann Stiftung's Transformation Index (BTI)), lack of data for some social indicators of Asian countries (i.e. Government expenditure on education, total (\% of GDP) etc.), limited time span of analysis, time constraints. 
Further directions of research: the construction of a "social indicator" and a "technological indicator", based on multiple estimates; analysis of the impact the indicators have on the informational efficiency of capital markets.

\section{References}

Balp, Gaia and Strampelli, Giovanni, Preserving Capital Markets Efficiency in the High-Frequency Trading Era (January 7, 2018). Bocconi Legal Studies Research Paper No. 3097723; Journal of Law, Technology and Policy, Forthcoming. Available at SSRN: https://ssrn.com/abstract=3097723 or http://dx.doi.org/10.2139/ssrn.3097723

Beran, Jan (1994). Statistics for Long-Memory Processes; Chapman \& Hall. (Section 6.1, p.116$119 ; 12.1 .3$, p.223 ff)

Kim, Jae H. \& Shamsuddin, Abul \& Lim, Kian-Ping, 2011. "Stock return predictability and the adaptive markets hypothesis: Evidence from century-long U.S. data," Journal of Empirical Finance, Elsevier, vol. 18(5), pages 868-879.

Kristoufek, Ladislav, and Miloslav Vosvrda. "Measuring Capital Market Efficiency: Long-Term Memory, Fractal Dimension and Approximate Entropy." The European Physical Journal B 87.7 (2014): n. pag. Crossref. Web.

Yentes, Jennifer \& Hunt, Nathaniel \& Schmid, Kendra \& Kaipust, Jeffrey \& Mcgrath, Denise \& Stergiou, Nicholas. (2012). The Appropriate Use of Approximate Entropy and Sample Entropy with Short Data Sets. Annals of biomedical engineering. 41. 10.1007/s10439-0120668-3.

Reisen, V. A., B. Abraham, and E. M. M. Toscano (2001) Parametric and semiparametric estimations of stationary univariate ARFIMA model. Brazilian Journal of Probability and Statistics 14, 185-206.

Rickles, Dean (2008) Econophysics and Financial Market Complexity

Stiglitz J.E. (2016) New Theoretical Perspectives on the Distribution of Income and Wealth Among Individuals. In: Basu K., Stiglitz J.E. (eds) Inequality and Growth: Patterns and Policy. International Economic Association Series. Palgrave Macmillan, London

The Worldwide Governance Indicators (WGI) project, http://info.worldbank.org/governance/wgi/ Virgilio, Gianluca. (2015). High-frequency trading and the efficient market hypothesis. 